\title{
JOHN RAWLS E A VISÃO INCLUSIVA DA RAZÃO PÚBLICA
}

\author{
Luiz Bernardo Leite Araujo \\ Universidade do Estado do Rio de Janeiro /CNPq
}

\begin{abstract}
The article presents John Rawls's growing interest on the relationship between religion and politics, from which it results an even more inclusive view of the public reason of political liberalism.
\end{abstract}

KEYWORDS: John Rawls, public reason, religion, secularism.

RESUMO: 0 artigo apresenta o crescente interesse de John Rawls pela relação entre religião e política, do qual resulta uma visão cada vez mais inclusiva da razão pública do liberalismo político.

PALAVRAS-CHAVE: John Rawls, razão pública, religião, secularismo.

$\mathrm{Na}$ "Introduction to the Paperback Edition" de seu Political Liberalism", redigida pouco mais de três anos após a primeira introdução de outubro de 1992, John Rawls notava de antemão um obstáculo na leitura da obra, inexistente em sua clássica $A$ Theory of Justice²: a identificação da questão filosófica. Enquanto nessa última tratava-se de apresentar os aspectos estruturais de uma teoria da justiça que, a partir da ideia do contrato social na tradição de Locke, Rousseau e Kant, funcionasse como a base moral mais apropriada para uma sociedade democrática, na obra de 1993 pretendia-se responder a uma

\footnotetext{
${ }^{1}$ RAWLS, J. Political Liberalism. New York: Columbia University Press, paperback edition with a new introduction and the "Reply to Habermas", 1996 [first edition: 1993].

${ }^{2}$ RAWLS, J. A Theory of Justice. Cambridge (Mass.): Harvard University Press, 1971. A edição definitiva da obra é agora a segunda edição, publicada em 1999 com novo prefácio de novembro de 1990 e uma tabela de conversão que permite ao leitor mover-se facilmente entre as duas edições. A nova tradução portuguesa é baseada na última edição revista pelo autor: Uma Teoria da Justiça. São Paulo: Martins Fontes, tradução de Jussara Simões, revisão técnica e da tradução de Álvaro de Vita, $3^{a}$ ed., 2008.
} 
importante questão resultante da combinação dos temas da justiça política e da tolerância: "Como é possível existir, ao longo do tempo, uma sociedade justa e estável de cidadãos livres e iguais, que permanecem profundamente divididos por doutrinas religiosas, filosóficas e morais razoáveis?”3. O obstáculo identificado pelo próprio Rawls residia no fato de que tal questão não fora formulada de modo claro e explícito ao apontar genericamente para o consenso sobreposto de doutrinas abrangentes razoáveis, sem chamar a atenção para o problema realmente espinhoso da compatibilidade pelas razões corretas de uma concepção política liberal e não religiosa com as doutrinas abrangentes razoáveis não liberais e religiosas. Assim, sumariando a intenção da obra de considerar a possibilidade e a coerência de um regime democrático constitucional estável e bem-ordenado, o filósofo americano identificou na particular atenção com as doutrinas religiosas o problema fundamental do liberalismo político, apresentando a questão filosófica por ele tratada da seguinte maneira: "Como é possível para aqueles que afirmam uma doutrina religiosa baseada na autoridade religiosa, por exemplo, a Igreja ou a Bíblia, assumir também uma concepção política razoável que sustente um regime democrático justo?"4.

Mas a Introdução de dezembro de 1995 não apenas identificava explicitamente a questão filosófica relacionada com o endosso dos ideais e valores políticos intrínsecos de uma concepção política liberal de justiça pelos cidadãos de fé, os quais devem aceitar um regime democrático como membros de um consenso sobreposto razoável, e não simplesmente como um modus vivendi entre forças políticas e sociais rivais. A segunda introdução também apresentava um guia de leitura que, entre outros aspectos, propunha uma revisão da ideia de razão pública exposta na sexta conferência do Liberalismo Político, cujo pleno acabamento viria a lume no último escrito rawlsiano ${ }^{5}$, de 1997. Ora, a principal mudança operada por Rawls na ideia de razão pública dizia respeito exatamente à questão de como as doutrinas abrangentes dos mais

\footnotetext{
${ }^{3}$ RAWLS, J. Political Liberalism, op. cit., p. 4 ["How is it possible for there to exist over time a just and stable society of free and equal citizens, who remain profoundly divided by reasonable religious, philosophical, and moral doctrines?"].

${ }^{4}$ Id., Ibid., p. xxxix ["How is it possible for those affirming a religious doctrine that is based on religious authority, for example, the Church or the Bible, also to hold a reasonable political conception that supports a just democratic regime?"].

${ }^{5}$ Cf. RAWLS, J. "The Idea of Public Reason Revisited". University of Chicago Law Review, 64 (1997): 765-807. O artigo corresponde ao Capítulo 26 de seus Collected Papers [Cambridge (Mass.): Harvard University Press, edited by Samuel Freeman, 1999, pp. 573-615], que servirão de referência ao presente trabalho.
} 
diversos tipos - religiosas e seculares - podem coexistir e cooperar de modo razoável e justo numa democracia constitucional, ou ainda quais são os pressupostos comuns para uma atuação aceitável dessas doutrinas distintas e incompatíveis na esfera pública. É nesse contexto que Rawls se refere pela primeira vez ao "proviso", especificando o que ele chama de visão ampla da razão pública e adotando uma visão mais inclusiva das razões abrangentes na discussão política. $\mathrm{Na}$ formulação mais recente, "doutrinas abrangentes razoáveis, religiosas ou não religiosas, podem ser introduzidas na discussão política pública a qualquer tempo, contanto que, na ocasião oportuna, sejam apresentadas razões políticas adequadas - e não razões dadas unicamente por doutrinas abrangentes - que sejam suficientes para sustentar tudo o que as doutrinas abrangentes introduzidas alegadamente sustentam"6.

$\mathrm{Na}$ realidade, os exemplos históricos do abolicionismo no século XIX e do movimento pelos direitos civis no século $\mathrm{XX}$, com as figuras exemplares de Abraham Lincoln e de Martin Luther King, já haviam persuadido Rawls de que a visão exclusiva, de acordo com a qual as "razões dadas explicitamente em termos de doutrinas abrangentes nunca devem ser introduzidas na razão pública"7, era por demais restritiva, de modo que "uma outra visão permitindo aos cidadãos, em certas situações, apresentar aquilo que consideram a base dos valores políticos enraizados em suas doutrinas abrangentes, desde que o façam de maneira a fortalecer o ideal da própria razão pública"8, já lhe parecia a mais correta. Distinguindo, porém, entre o caso ideal de uma sociedade mais ou menos bem-ordenada sem conflitos graves, o caso de uma sociedade desse tipo com séria disputa em torno da aplicação de algum princípio de justiça, e mais o caso de uma sociedade que, além de não ser bem-ordenada, enfrenta profunda divisão em matéria constitucional, como nos exemplos da escravidão e da segregação racial, Rawls ainda estipulava condições para a introdução de doutrinas abrangentes na razão pública, as quais seriam integralmente abolidas

\footnotetext{
${ }^{6}$ RAWLS, J. "The Idea of Public Reason Revisited", in: Collected Papers, op. cit., p. 591 ["reasonable comprehensive doctrines, religious or nonreligious, may be introduced in public political discussion at any time, provided that in due course proper political reasons - and not reasons given solely by comprehensive doctrines - are presented that are sufficient to support whatever the comprehensive doctrines introduced are said to support"]. Cf. tb. RAWLS, J. Political Liberalism, op. cit., pp. li-lii.

${ }^{7}$ RAWLS, J. Political Liberalism, op. cit., p. 247 ["reasons given explicitly in terms of comprehensive doctrines are never to be introduced into public reason"].

8 Id., Ibid. ["another view allowing citizens, in certain situations, to present what they regard as the basis of political values rooted in their comprehensive doctrines, provided they do this in ways that strengthen the ideal of public reason itself"].
} 
pela visão inclusiva adotada a partir da segunda introdução do Political Liberalism. Convencido de que "os limites apropriados da razão pública variam, conforme as condições históricas e sociais", e de que "a concepção política de justiça e o ideal de honrar a razão pública apoiam-se mutuamente"10, Rawls passa a adotar tão somente a cláusula que prescreve a apresentação pública de razões estritamente políticas (no devido tempo) pelas doutrinas abrangentes, razões igualmente acessíveis a todos os cidadãos.

Trata-se claramente de uma interpretação mais permissiva da razão pública, a qual, não obstante, permanece sujeita a muitos questionamentos decorrentes de seu caráter ainda restritivo. Destarte, Rawls lança mão de uma intrincada argumentação a fim de contrapor-se a três objeções à razão pública do liberalismo político, segundo as quais ela limitaria as considerações e os tópicos disponíveis para o debate político, evitaria a questão da verdade em nome do politicamente razoável e simplesmente corroboraria a harmonia e a concórdia já existente numa democracia constitucional bem-estabelecida ${ }^{11}$. Longe de acreditar na reconciliação integral pela razão pública, Rawls invoca sua capacidade de resolução ou, ao menos, de mitigação dos conflitos entre os cidadãos, afirmando tratar-se de uma ideia inteiramente pertencente à categoria do político, cujo conteúdo é dado não por uma - sequer pela justiça como equidade -, mas por uma família de concepções políticas de justiça. A ideia de razão pública diz respeito ao tipo de razões em que os cidadãos baseiam seus argumentos políticos no processo de justificação de normas que, referidas a elementos constitucionais essenciais e a questões de justiça básica ${ }^{12}$, invocam o

9 Ibid., p. 251 ["the appropriate limits of public reason vary, depending on historical and social conditions"].

$10 \mathrm{Ibid}$., p. 252 ["the political conception of justice and the ideal of honoring public reason mutually support one another"].

${ }^{11}$ Cf. RAWLS, J. Collected Papers, op. cit., pp. 601-611. Sobre o que segue, valho-me parcialmente de meu artigo: ARAUJO, L. B. L. "Razão pública e pós-secularismo: apontamentos para o debate". Ethic@, 8 (2009): 155-173.

12 Essas questões de justiça política fundamental, que constituem o objeto da razão pública, são assim descritas por Rawls (Political Liberalism, op. cit., p. I, n. 23): "Os elementos constitucionais essenciais dizem respeito a questões sobre quais direitos e liberdades políticas, digamos, podem ser incluídos razoavelmente em uma constituição escrita, quando se supõe que a constituição pode ser interpretada por uma corte suprema, ou algum corpo similar. Questões de justiça básica se referem à estrutura básica da sociedade e, assim, diriam respeito a questões de economia básica e de justiça social, e outras coisas não abrangidas por uma constituição" ["Constitutional essentials concern questions about what political rights and liberties, say, may reasonably be included in a written constitution, when assuming the constitution may be interpreted by a supreme court, or some similar body. Matters of basic justice relate to the basic structure of society and so would concern questions of basic economic and social justice and other things not covered by a constitution"]. 
emprego efetivo da coerção pública pelo poder político. Seu ingrediente essencial é o critério de reciprocidade, cuja exigência é a de que "quando os termos da justa cooperação são propostos como os mais razoáveis, aqueles que os propõem devem pensar que é, pelo menos, razoável para outros aceitá-los como cidadãos livres e iguais, e não como dominados ou manipulados ou sob pressão causada por uma posição política ou social inferior"13. O importante, dirá Rawls em uma entrevista concedida em 1998, "é que as pessoas ofereçam os tipos de razões que possam ser compreendidas e avaliadas para além de suas doutrinas abrangentes particulares. Assim, a ideia de razão pública não é sobre as respostas certas a todas essas questões, mas sobre os tipos de razões com as quais elas deveriam ser respondidas" 14 .

A razão pública rawlsiana de modo algum exige que os cidadãos, ao ingressarem no fórum político público para discutir e decidir questões fundamentais de justiça política, deixem para trás os valores seculares ou religiosos que prezam, restringindo-se à avaliação daquilo que deve contar como argumento aceitável, tendo em vista o fato do pluralismo e a suposição do caráter razoável dos indivíduos. $\mathrm{Na}$ mesma entrevista, Rawls assinala que "as pessoas podem utilizar argumentos da Bíblia, se quiserem. Mas eu quero que elas vejam que também deveriam ofertar argumentos com os quais todos os cidadãos razoáveis poderiam concordar. Mais uma vez, qual é a alternativa? Como se pode conviver em um regime constitucional com todas essas outras doutrinas abrangentes?"15. Por essa razão, o acordo público está relacionado com os valores políticos que convergem para uma concepção política comum às doutrinas abrangentes razoáveis e que determinam as relações de um governo democrático com seus cidadãos e destes entre si. Neste sentido, Rawls é incisivo quanto à aplicação da razão pública na "cultura política pública", que se refere à

13 RAWLS, J. The Law of Peoples. Cambridge (Mass.), Harvard University Press, 1999, p. 14 ["when terms are proposed as the most reasonable terms of fair cooperation, those proposing them must think it at least reasonable for others to accept them, as free and equal citizens, and not as dominated or manipulated or under pressure caused by an inferior political or social position"].

${ }^{14}$ RAWLS, J. "Commonweal Interview with John Rawls", in: Collected Papers, op. cit., pp. 616-622 [aqui, p. 619: "What's important is that people give the kinds of reasons that can be understood and appraised apart from their particular comprehensive doctrines. So the idea of public reason isn't about the right answers to all these questions, but about the kinds of reasons that they ought to be answered by]. A entrevista foi concedida em janeiro de 1998 e publicada originalmente em uma revista católica liberal: Commonweal, v. 125, n. 16 (September 25, 1998): 12-17.

${ }^{15}$ Id., Ibid., p. 620 ["People can make arguments from the Bible if they want to. But I want them to see that they should also give arguments that all reasonable citizens might agree to. Again, what's the alternative? How are you going to get along in a constitutional regime with all these other comprehensive doctrines?"]. 
sociedade política onde os cidadãos agem como se fossem legisladores ${ }^{16}$, em contraste com a "cultura de fundo" (background culture), formada pelas instituições e associações da sociedade, como a família, empresas, igrejas, sindicatos, universidades, entre outras, cuja cultura é permeada por razões não públicas ${ }^{17}$. Rawls enfatiza que "a introdução de doutrinas religiosas e seculares na cultura política pública, desde que a cláusula (proviso) seja cumprida, não altera a natureza e o conteúdo da justificação na própria razão pública”, justificação que permanece adstrita a uma família de concepções políticas razoáveis de justiça e não impõe "restrições ou exigências em como as doutrinas religiosas ou seculares devem ser expressas; tais doutrinas não precisam, por exemplo, ser logicamente corretas por alguns padrões, abertas à apreciação racional ou demonstráveis"18.

A rigor, o liberalismo político não apenas não impede a introdução de doutrinas abrangentes no fórum político público, como também admite que a revelação recíproca de razões não públicas contribui para o aperfeiçoamento da discussão política e fortalece o ideal da razão pública, uma vez que "o conhecimento mútuo pelos cidadãos de suas doutrinas religiosas e não religiosas expressas na visão ampla da cultura política pública reconhece que as raízes do compromisso democrático dos cidadãos com suas concepções políticas repousam nas suas respectivas doutrinas abrangentes, religiosas e não religiosas. Assim, o compromisso dos cidadãos com o ideal democrático da razão pública é

16 Trata-se aqui do ideal de razão pública, concretizado quando os cidadãos se vêem como legisladores e cumprem o seu dever moral (não jurídico) de civilidade, distinto da ideia de razão pública, aplicada aos juízes, especialmente de uma corte suprema, aos funcionários de governo, particularmente executivos e legisladores, e aos candidatos a cargo público e seus chefes de campanha. Sobre o fórum político público e sua divisão tripartite, cf. RAWLS, J. Collected Papers, op. cit., pp. 574-577. Em relação à Corte Suprema como exemplar da razão pública, cf. Political Liberalism, op. cit., pp. 231-240.

17 A cultura de fundo compreende todas as doutrinas abrangentes presentes numa sociedade democrática. É a cultura do social, e não do político, permeada por razões não públicas, o que não quer dizer razões privadas, pois a distinção entre público e privado é ignorada por Rawls (cf. Polítical Liberalism, op. cit., pp. 220-222). Rawls distingue ainda, a bem dizer, a "cultura política não pública", que faz a mediação entre a cultura política pública e a cultura de fundo e abrange os chamados meios de comunicação (cf. Collected Papers, op. cit., p. 576, n. 13). Esses últimos e aquelas instituições e associações da sociedade não estão sujeitas aos limites da razão pública, salvo quando afetam direitos e liberdades fundamentais da cidadania (cf. tb. RAWLS, J. Justice as Fairness: a Restatement. Cambridge (Mass.): The Belknap Press of Harvard University, edited by Erin Kelly, 2001, pp. 164-166).

${ }^{18}$ RAWLS, J. Collected Papers, op. cit., p. 592 ["the introduction into public political culture of religious and secular doctrines, provided the proviso is met, does not change the nature and content of justification in public reason itself. (...) there are no restrictions or requirements on how religious or secular doctrines are themselves to be expressed; these doctrines need not, for example, be by some standards logically correct, or open to rational appraisal, or evidentially supportable"]. 
fortalecido pelas razões corretas. Podemos pensar nas doutrinas abrangentes razoáveis que sustentam concepções políticas razoáveis de sociedade como a base social vital dessas concepções, conferindo-lhes força e vigor duradouros. Quando essas doutrinas aceitam a cláusula (proviso) e só então entram no debate político, o comprometimento com a democracia constitucional é publicamente manifestado"19. A exigência que permanece a todo instante, como se nota, consiste em traduzir os argumentos morais, filosóficos e religiosos utilizados no processo de justificação normativa para a linguagem do político, igualmente acessível a todos os cidadãos. Entretanto, a despeito de assinalar razões positivas para a introdução das doutrinas abrangentes na discussão política pública, Rawls se sujeita a inúmeras críticas derivadas dessa ressalva de tradutibilidade, particularmente no que se refere às razões religiosas. É claro que o ônus recai também sobre razões seculares - expressas em termos de doutrinas morais ou filosóficas, as quais não se confundem com a razão pública propriamente dita e os seus valores estritamente políticos -, mas as cargas do juízo (burdens of judgment) distribuídas simetricamente entre os membros da sociedade democrática, na qual a afirmação de muitas doutrinas abrangentes e suas legítimas pretensões de verdade promove o desacordo razoável entre as pessoas, parecem onerar sobremaneira os cidadãos religiosos ${ }^{20}$.

De fato, o próprio Rawls em suas reflexões sobre religião e razão pública na democracia levanta essa intrigante questão em relação a cidadãos que sustentam doutrinas religiosas como cidadãos de fé: "Como é possível para cidadãos de fé serem membros dedicados de uma sociedade democrática, que endossam os ideais e os valores políticos intrínsecos da sociedade e não

\footnotetext{
19 Id., Ibid. ["Citizens' mutual knowledge of one another's religious and nonreligious doctrines expressed in the wide view of public political culture recognizes that the roots of democratic citizens' allegiance to their political conceptions lie in their respective comprehensive doctrines, both religious and nonreligious. In this way citizens' allegiance to the democratic ideal of public reason is strengthened for the right reasons. We may think of the reasonable comprehensive doctrines that support society's reasonable political conceptions as those conceptions' vital social basis, giving them enduring strength and vigor. When these doctrines accept the proviso and only then come into political debate, the commitment to constitutional democracy is publicly manifested"].

${ }^{20}$ Malgrado muitas discordâncias quanto a seu impacto e a maneira de lidar com as assimetrias dela decorrentes, tal sobrecarga sobre cidadãos religiosos constitui um diagnóstico compartilhado por diversos críticos da razão pública rawlsiana, tornando sua posição central, como veremos, nos debates atuais sobre religião na esfera pública. Vide, p. ex.: BOETTCHER, J. "Public reason and religion", in: BROOKS, T.; FREYENHAGEN, F. (eds.). The Legacy of John Rawls. London: Continuum, 2007, pp. 124-151.
} 
simplesmente aquiescem ao equilíbrio das forças políticas e sociais?"21. A questão é formulada com maior nitidez da seguinte forma: "Como é possível se é que é possível - que os fiéis, assim como os não religiosos (seculares), endossem um regime constitucional mesmo quando suas próprias doutrinas abrangentes podem não prosperar nele e podem, inclusive, declinar?”22. Trata-se do problema da delimitação entre tipos de razões que possam assegurar uma estabilidade de nível superior, ou seja, fundada no firme compromisso com os valores políticos de uma sociedade democrática pluralista, e não na mera aceitação de um modus vivendi entre doutrinas rivais. Sem deixar de rejeitar a identificação entre razão pública e razão secular ${ }^{23}$, Rawls destaca fortemente que os conflitos entre religião e democracia no mundo contemporâneo suscitam, de modo especial, a questão torturante de saber se a democracia e as doutrinas abrangentes podem ser compatíveis e como o podem. Para respondê-la, ele distingue entre concepção política e doutrinas abrangentes, sustentando uma separação clara entre as razões não públicas das últimas e a razão pública da primeira, da qual decorre não apenas a neutralidade do poder político em face das doutrinas abrangentes razoáveis, mas também a injunção restritiva do uso público da razão pelos cidadãos, cujas doutrinas filosóficas, morais e religiosas são contidas nos limites de princípios políticos razoáveis que permitem mitigar os conflitos potenciais entre as doutrinas abrangentes, notadamente entre a religião e a ordem democrática constitucional e entre as próprias doutrinas religiosas ${ }^{24}$.

O foco do pensamento rawlsiano na especificação da política democrática e no papel das crenças religiosas na vida pública é predominante nos debates contemporâneos sobre a relação entre religião e política, uma questão clássica da filosofia prática. Independentemente da avaliação que se faça

${ }^{21}$ RAWLS, J. Collected Papers, op. cit., p. 588 ["How is it possible for citizens of faith to be wholehearted members of a democratic society who endorse society's intrinsic political ideals and values and do not simply acquiesce in the balance of political and social forces?"].

22 Id., Ibid., pp. 588-589 ["How is it possible - or is it - for those of faith, as well as the nonreligious (secular), to endorse a constitutional regime even when their comprehensive doctrines may not prosper under it, and indeed may decline?"].

${ }^{23}$ Cf. Ibid., p. 583 e p. 587.

24 Rawls nega enfaticamente que seus argumentos sejam uma forma velada de secularismo, considerando, não sem alguma ironia, que eles poderiam ser vistos como uma forma velada de religiosidade, o que também não é o caso. A seu juízo, há dois tipos de doutrinas abrangentes, religiosas e seculares, sendo os argumentos políticos em termos de razão pública o solo comum entre elas, a partir do qual é possível a compreensão e a cooperação mútuas. Sobre isso, cf. "Commonweal Interview...", in: Ibid., pp. 619-620. Sobre o tema da religião em Rawls, cf. DOMBROWSKI, D. Rawls and Religion: The Case for Political Liberalism. Albany: State University of New York Press, 2001. 
da concepção de cidadania democrática e da ideia de razão pública nele inscritas, o liberalismo político de John Rawls tornou-se uma espécie de abordagem padrão na questão da religião na esfera pública, não havendo exceção na imensa literatura sobre o assunto que não reconheça que o estado da arte é amplamente definido pelos termos com os quais o mais influente filósofo político do último século retoma a recorrente discussão sobre a relação entre política e religião ${ }^{25}$. É chamada de abordagem padrão por ser aquela apoiada em noções de legitimidade política e de ética da cidadania claramente vigentes nas democracias constitucionais bem-estabelecidas. Em breves palavras, é a abordagem que - adotando uma justificação normativa não sectária fundada em razões publicamente acessíveis, por um lado, e requerendo dos cidadãos certa moderação no uso de argumentos direta e exclusivamente religiosos ao tratarem do exercício do poder coercitivo e dos termos fundamentais da cooperação política, por outro lado - acarreta uma interpretação restritiva do papel político da religião. No entanto, o estudioso deve acautelar-se quanto às confusões terminológicas geradas pela tentativa de se estabelecer uma tipologia ideal no tratamento do tema. Há uma tendência, com efeito, de separar em duas categorias as respostas à questão sobre se, e em que medida, a religião deveria desempenhar um papel na política democrática ${ }^{26}$ : exclusivista ou separatista versus inclusivista ou integracionista. Tende-se igualmente, além disso, a identificar a referida abordagem padrão com a primeira visão ${ }^{27}$, que preconiza

${ }^{25}$ Para uma avaliação crítica do tema a partir do pensamento de Rawls, por ordem de aparição, cf. GREENAWALT, K. Religious Convictions and Political Choice. Oxford: Oxford University Press, 1988; Id. Private Consciences and Public Reasons. Oxford: Oxford University Press, 1995; AUDI, R. and WOLTERSTORFF, N. (eds.). Religion in the Public Square: The Place of Religious Convictions in Political Debate. Lanham: Rowman \& Littlefield, 1997; WEITHMAN, P. J. (ed.). Religion and Contemporary Liberalism. Notre Dame: Notre Dame University Press, 1997; GEORGE, R. P. and WOLFE, C. (eds.). Natural Law and Public Reason. Washington: Georgetown University Press, 2000; AUDI, R. Religious Commitment and Secular Reason. Cambridge: Cambridge University Press, 2000; WEITHMAN, P. J. Religion and the Obligations of Citizenship. Cambridge: Cambridge University Press, 2002; EBERLE, C. Religious Conviction in Liberal Politics. Cambridge: Cambridge University Press, 2002; STOUT, J. Democracy and Tradition. Princeton: Princeton University Press, 2003; CUNEO, T. (ed.). Religion in the Liberal Polity. Notre Dame: University of Notre Dame Press, 2004; SWAINE, L. The Liberal Conscience: Politics and Principle in a World of Religious Pluralism. New York: Columbia University Press, 2005; DOSTERT, T. Beyond Political Liberalism: Toward a Post-Secular Ethics of Public Life. Notre Dame: University of Notre Dame Press, 2006; McGRAW, B. Faith in Politics: Religion and Liberal Democracy. Cambridge: Cambridge University Press, 2010.

${ }^{26}$ Uma boa antologia de textos baseada na referida tipologia ideal é a seguinte: CLANTON, J. (ed.) The Ethics of Citizenship: Liberal Democracy and Religious Convictions. Waco (Texas): Baylor University Press, 2009.

${ }^{27}$ Somente a título de ilustração, registre-se a seguinte passagem de uma obra recente: "It is hardly an exaggeration to say that the very point of "public reason" is to keep public discourse shallow - to keep it 
manter a religião e a política em esferas distintas e separadas, preferencialmente incomunicáveis.

Contudo, há gradações consideráveis entre o "exclusivismo", segundo o qual as doutrinas religiosas não deveriam desempenhar nenhum papel em discussões políticas e em tomadas de decisões públicas, e o "inclusivismo", que argumenta em favor do legítimo papel desempenhado pelas convicções religiosas dos cidadãos na política democrática e para o qual não deveria haver qualquer restrição ex-ante com respeito às justificações religiosas no espaço público. Ademais, se a minha interpretação do liberalismo político estiver correta, não há como identificar a posição de Rawls com a visão separatista, de modo que a abordagem padrão na questão da religião na esfera pública, caso seja acertado considerar a razão pública rawlsiana como seu modelo principal, é mais bem descrita como uma espécie de inclusivismo fraco ou moderado. Isso porque, como observado, as restrições da razão pública são aquelas que os seguidores de doutrinas abrangentes, religiosas e não religiosas, podem razoavelmente endossar a partir do critério de reciprocidade democrática que obriga os cidadãos, crentes e não crentes, a honrar o dever de civilidade e explicar aos outros cidadãos as suas razões para sustentar posições políticas fundamentais em função da concepção política de justiça que pensam ser a mais razoável, admitindo inclusive o benefício da introdução de doutrinas abrangentes, bem como do conhecimento mútuo de suas razões filosóficas, morais e religiosas, na discussão política pública. O desafio, então, é reconhecer as variações entre os tipos ideais de tratamento da questão da religião na esfera pública e avaliar os argumentos revisionistas contra a interpretação restritiva do papel político da religião e sua clássica delimitação de fronteiras entre o secular e o religioso. É uma tarefa que, evidentemente, escapa ao escopo do presente artigo.

De qualquer forma, embora Rawls seja o mais proeminente de seus representantes e tenha descortinado, por assim dizer, uma fecunda trilha de investigação com sua ideia de razão pública, a abordagem padrão, entendida do modo acima enunciado, é aquela que predomina nas controvérsias sobre religião e democracia e conta com diversos protagonistas, dentre os quais poderíamos destacar os seguintes pensadores: Bruce Ackerman, Charles Larmore, Stephen

from drowning in the perilous depths of questions about "the nature of the universe", or "the end and the object of life", or other tenets of our comprehensive doctrines" (SMITH, S. The Disenchantment of Secular Discourse. Cambridge (Mass.): Harvard University Press, 2010, p. 17. 
Macedo, Thomas Nagel e Richard Rorty ${ }^{28}$. No mesmo diapasão, é possível agrupar sob a denominação de inclusivismo forte, identificando-o com a abordagem integracionista antes assinalada, uma plêiade de autores cujo foco principal é exatamente a crítica da visão dita separatista ou exclusivista e sua contestável descrição do papel e do significado da religião na esfera pública ${ }^{29}$. Tendo como alvo privilegiado a razão pública do liberalismo político, as objeções mais salientes contra uma determinação restritiva do uso público das razões religiosas dizem respeito notadamente: (a) aos critérios normativos e epistêmicos de sua concepção de justificação política; (b) à viabilidade do exercício moderado e nuançado de distinções, avaliações e adequações entre razões e argumentos que não levem em conta as motivações profundas do raciocínio moral e político, algo especialmente implausível para cidadãos ordinários com fortes convicções religiosas; (c) à distribuição injusta dos deveres de cidadania entre cidadãos religiosos e não religiosos, na medida em que os argumentos dos primeiros seriam mais facilmente detectáveis por serem mais claramente não públicos, além de menos espontaneamente congruentes com o conteúdo da razão pública e, assim, sujeitos a exames mais desconfiados e frequentes; (d) à incompatibilidade entre a injunção restritiva do uso público da razão e a característica totalizadora das crenças religiosas, existencialmente definidoras da identidade das pessoas crentes e das comunidades de fé, tratandose aqui da objeção denominada integralista, estreitamente vinculada às duas anteriores; (e) à realização efetiva da cidadania democrática, que seria enfraquecida pela ausência ou pela diminuição do engajamento religioso contra

\footnotetext{
${ }^{28}$ Cf. ACKERMAN, B. We The People: Foundations. Cambridge (Mass.): Harvard University Press, 1993; Id. We The People: Transformations. Cambridge (Mass.): Harvard University Press, 2000; LARMORE, C. The Morals of Modernity. Cambridge: Cambridge University Press, 1996; Id. The Autonomy of Morality. Cambridge: Cambridge University Press, 2008; MACEDO, S. "Liberal Civic Education and Religious Fundamentalism: The Case of God v. John Rawls?", Ethics, v. 105, n. 3 (1995): 468-96; Id. Diversity and Distrust: Civic Education in a Multicultural Democracy. Cambridge (Mass.): Harvard University Press, 2003; NAGEL, T. Equality and Partiality. Oxford: Oxford University Press, 1991; Id. Secular Philosophy and the Religious Temperament. Oxford: Oxford University Press, 2009; RORTY, R. "Religion as Conversation-stopper", in: Philosophy and Social Hope. New York: Penguin, 2000, pp. 168-174; Id. "Religion in the Public Square: A Reconsideration", Journal of Religious Ethics, v. 31, n. 1 (2003): 141149; Id. An Ethics for Today: Finding Common Ground Between Philosophy and Religion. New York: Columbia University Press, 2010.

${ }^{29}$ Os principais representantes do aqui denominado inclusivismo "forte" são Christopher Eberle, Kent Greenawalt, Michael Perry, Michael Sandel e Paul Weithman. Vide a bibliografia da nota 25, acrescentando-se: SANDEL, M. Public Philosophy: Essays on Morality in Politics. Cambridge (Mass.): Harvard University Press, 2005; Id. Justice: What's the Right Thing to Do? New York: Farrar, Straus and Giroux, 2009.
} 
as injustiças e empobrecida sem os benefícios deliberativos de formas diferenciadas e não conformistas de opiniões na discussão política pública ${ }^{30}$.

Grosso modo, portanto, a posição de Rawls nos debates contemporâneos sobre a relação entre política e religião, apesar de sujeita às referidas objeções em decorrência da cláusula restritiva da razão pública, deve ser situada entre a visão exclusiva e a visão inclusiva, consideradas como tipos ideais e respectivamente representadas (mais claramente do que nos autores antes citados) por Robert Audi e Nicholas Wolterstorff ${ }^{31}$. O primeiro pretende defender uma interpretação restritiva do papel político da religião apoiada no princípio de justificação secular que obriga os cidadãos crentes a estabelecer uma espécie de "equilíbrio ético-teológico" (theo-ethical equilibrium) entre suas convicções religiosas e seculares. O segundo sustenta a ampla abertura da discussão política pública às razões religiosas não traduzidas com base no igual respeito pelas pessoas que encaram a totalidade de sua existência a partir da fé, as quais, longe de serem capazes de adotar a forma de abstinência epistêmica requerida pela razão secular, vêem-se obrigadas a fundar suas decisões políticas em suas convicções religiosas. Rawls, por seu turno, adota uma concepção puramente política dentro do conteúdo da razão pública, submetendo tanto os argumentos religiosos quanto os

30 Tais objeções à interpretação restritiva do papel político da religião despontam em importantes números especiais de periódicos, reunindo contribuições apresentadas em eventos sobre a questão da religião na esfera pública: "The role of religion in public debate in a liberal society", San Diego Law Review, 30 (1993): 643-916; "The religious voice in the public square", Loyola of Los Angeles Law Review, 29 (1996): 1401-1542; "Religion and politics", Social Theory and Practice, 31 (2005): 157-304; "Religion and the public sphere", Philosophy and Social Criticism, 35 (2009): 5-238; "Constitutionalism and secularism in an age of religious revival: the challenge of global and local fundamentalisms", Cardozo Law Review, 30 (2009): 2331-2896; "Post-secularism and multicultural jurisdictions", Philosophy and Social Criticism, 36 (2010): 261-516.

${ }^{31}$ É bastante esclarecedor, neste sentido, o intercâmbio entre os dois autores na obra Religion in the Public Square, citada na nota 25. Ela é composta de longos ensaios escritos por cada um deles sobre 0 tema da relação entre religião e política, seguidos de breves ensaios críticos de um autor sobre o outro e de um comentário final acerca dos pontos de acordo e de desacordo entre Audi e Wolterstorff. Esses pensadores aparecem como representativos de posições antagônicas na concepção habermasiana do uso público da razão, cuja finalidade principal consiste em mediar entre a interpretação restritiva do papel político da religião e as propostas revisionistas que atingem os fundamentos do Estado democrático de direito, propondo uma nova delimitação de fronteiras que supere as objeções frequentemente erguidas contra a ideia rawlsiana de razão pública, seja a de que os cidadãos religiosos carregam um fardo injusto de autocensura ao terem de separar suas identidades religiosa e não religiosa, seja a de que os deveres de cidadania são desigualmente distribuídos entre cidadãos crentes e seculares (cf. HABERMAS, J. "Religião na esfera pública. Pressuposições cognitivas para o 'uso público da razão' de cidadãos seculares e religiosos", in: Entre naturalismo e religião: estudos filosóficos. Rio de Janeiro: Tempo Brasileiro, 2007, pp. 129-167). 
argumentos seculares, pertencentes à filosofia primeira e à doutrina moral, à mesma restrição enunciada no "proviso", de acordo com uma ideia também puramente política de tolerância que, mesmo podendo ser expressa a partir de uma doutrina religiosa ou não religiosa, seja compatível com o critério de reciprocidade, base fundamental da compreensão e da aceitação pelas doutrinas abrangentes "de que, a não ser endossando uma democracia constitucional razoável, não há outra maneira de assegurar imparcialmente a liberdade dos seus adeptos consistente com as liberdades iguais de outros cidadãos livres e iguais razoáveis" 32 . Ao que tudo indica, a ideia de razão pública em Rawls representa uma mediação entre os dois lados, rejeitando ao mesmo tempo o secularismo dogmático e o fundamentalismo religioso como justificações aceitáveis para o problema crucial da legitimidade política em sociedades marcadas pelo pluralismo de doutrinas morais, filosóficas e religiosas, cujo desacordo razoável é característico de uma cultura política democrática.

\section{REFERÊNCIAS BIBLIOGRÁFICAS}

ARAUJO, L. B. L. "Razão pública e pós-secularismo: apontamentos para o debate”. Ethic@, 8 (2009): 155-173.

AUDI, R. and WOLTERSTORFF, N. (eds.). Religion in the Public Square: The Place of Religious Convictions in Political Debate. Lanham: Rowman \& Littlefield, 1997.

Religious Commitment and Secular Reason. Cambridge: Cambridge University Press, 2000.

BOETTCHER, J. "Public reason and religion", in: BROOKS, T.; FREYENHAGEN, F. (eds.). The Legacy of John Rawls. London: Continuum, 2007.

CLANTON, J. (ed.) The Ethics of Citizenship: Liberal Democracy and Religious Convictions. Waco (Texas): Baylor University Press, 2009.

\footnotetext{
32 RAWLS, J. Collected Papers, op. cit., p. 590 ["that, except by endorsing a reasonable constitutional democracy, there is no other way fairly to ensure the liberty of its adherents consistent with the equal liberties of other reasonable free and equal citizens"].
} 
CUNEO, T. (ed.). Religion in the Liberal Polity. Notre Dame: University of Notre Dame Press, 2004.

DOSTERT, T. Beyond Political Liberalism: Toward a Post-Secular Ethics of Public Life. Notre Dame: University of Notre Dame Press, 2006

EBERLE, C. Religious Conviction in Liberal Politics. Cambridge: Cambridge University Press, 2002.

GEORGE, R. P. and WOLFE, C. (eds.). Natural Law and Public Reason. Washington: Georgetown University Press, 2000.

GREENAWALT, K. Religious Convictions and Political Choice. Oxford: Oxford University Press, 1988.

. Private Consciences and Public Reasons. Oxford: Oxford University Press, 1995.

McGRAW, B. Faith in Politics: Religion and Liberal Democracy. Cambridge: Cambridge University Press, 2010.

RAWLS, John. A Theory of Justice. Original Edition. Cambridge, Mass.: Harvard University Press, 1971.

A Theory of Justice. Revised Edition. Cambridge, Mass.: Harvard University Press, 1999.

. Political Liberalism. New York: Columbia University Press, 1996.

. The Law of Peoples. Cambridge, Mass.: Harvard University Press, 2001.

. Collected Papers. Ed. S. Freeman. Cambridge, Mass.: Harvard University Press, 1999.

. Justice as Fairness: A Restatement. Ed. E. Kelly. Cambridge, Mass.: Harvard University Press, 2001.

. A Study on the Grounds of Ethical Knowledge: Considered with Reference to Judgments on the Moral Worth of Character. PhD. Dissertation. Princeton University, 1950.

STOUT, J. Democracy and Tradition. Princeton: Princeton University Press, 2003. 
SWAINE, L. The Liberal Conscience: Politics and Principle in a World of Religious Pluralism. New York: Columbia University Press, 2005.

WEITHMAN, P. J. (ed.). Religion and Contemporary Liberalism. Notre Dame: Notre Dame University Press, 1997. Religion and the Obligations of Citizenship. Cambridge: Cambridge University Press, 2002. 